\title{
Association between the type of physical activity and metabolic syndrome in middle- aged and older adult residents of a semi- mountainous area in Japan
}

\author{
Noriko Kudo* (D, Ritsuko Nishide, Mayumi Mizutani, Shota Ogawa and Susumu Tanimura
}

\begin{abstract}
Background: Physical activity is reported to prevent metabolic syndrome. However, it is unclear whether exercise or daily physical activity is more beneficial for residents of semi-mountainous areas. This study aimed to identify whether daily physical activity is more beneficial than exercise for the prevention of metabolic syndrome among middle-aged and older residents in semi-mountainous areas.
\end{abstract}

Methods: We analyzed secondary data of 636 people who underwent a specific health checkup in a semimountainous area of Japan. Physical activity was classified into four types: inactivity (I-type; without exercise and without daily physical activity), only exercise (E-type; with exercise and without daily physical activity), only daily physical activity (D-type; without exercise and with daily physical activity), and full physical activity type (F-type; with exercise and with daily physical activity). We compared the means of risk factors for metabolic syndrome by these four types, followed by logistic regression analysis, to identify whether and to what extent the D-type was less likely to have metabolic syndrome than the E-type.

Results: The prevalence of metabolic syndrome was $28.5 \%$ (men $45.7 \%$, women 15.8\%). The proportions of men with exercise and daily physical activity were $38.7 \%$ and $52.8 \%$, respectively. For women, the proportions were $33.0 \%$ and $47.1 \%$, respectively. In women, the D-type had the significantly lowest BMI, smallest waist circumference, highest HDL-C, and lowest prevalence of metabolic syndrome of the four types; the same was not observed in men. Additionally, D-type activity was more strongly associated with a reduced risk of metabolic syndrome than Etype activity in women (adjusted odds ratio $0.24 ; 95 \%$ confidence interval $0.06-0.85, P=0.028$ ).

Conclusions: Compared to middle-aged and older women residents with exercise in a semi-mountainous area of Japan, those with daily physical activity may effectively prevent metabolic syndrome.

Keywords: Exercise, Daily physical activity, Metabolic syndrome, Women

\footnotetext{
* Correspondence: 318D102@m.mie-u.ac.jp

Department of Public Health Nursing, Mie University Graduate School of

Medicine, 2-174 Edobashi, Tsu, Mie 514-8507, Japan
}

C The Author(s). 2021 Open Access This article is licensed under a Creative Commons Attribution 4.0 International License, which permits use, sharing, adaptation, distribution and reproduction in any medium or format, as long as you give appropriate credit to the original author(s) and the source, provide a link to the Creative Commons licence, and indicate if changes were made. The images or other third party material in this article are included in the article's Creative Commons licence, unless indicated otherwise in a credit line to the material. If material is not included in the article's Creative Commons licence and your intended use is not permitted by statutory regulation or exceeds the permitted use, you will need to obtain permission directly from the copyright holder. To view a copy of this licence, visit http://creativecommons.org/licenses/by/4.0/. The Creative Commons Public Domain Dedication waiver (http://creativecommons.org/publicdomain/zero/1.0/) applies to the data made available in this article, unless otherwise stated in a credit line to the data. 


\section{Background}

A recently published systematic review showed a positive association between physical inactivity and metabolic syndrome [1]. In 2016, the prevalence of insufficient physical activity was $35.5 \%$ among adults (age $\geq 18$ years; $37.0 \%$ for women, $33.8 \%$ for men) in Japan, which is higher than the global average (27.5\%) $[2,3]$. Therefore, physical activity promotion is important for the prevention of metabolic syndrome and its components [4].

Physical activity refers to "any bodily movement produced by skeletal muscles requiring energy expenditure" $[5,6]$ and is classified into two types: daily physical activity and exercise [7]. Daily physical activity includes activities undertaken daily, such as working, performing household chores, and traveling, whereas exercise includes planned, structured, and repetitive activities, such as sports [5].

Systematic reviews and meta-analyses have shown that exercise $[8,9]$ and leisure-time physical activity [10] are beneficial in preventing and improving the major causes of death-related chronic illnesses, including metabolic syndrome. Besides the benefits of exercise, the health risks associated with inactivity [11] and the importance of interrupting sedentary behavior [12] have been added to the World Health Organization's new guidelines and evidence profile on physical activity and sedentary behavior [13-15].

However, there is no robust evidence that examined which of the two types of activity, namely, exerciserelated activity or daily physical activity, effectively prevents metabolic syndrome.

Several studies have shown that rural residents are less likely to be physically active than urban residents [1618]. Rural areas tend to lack public transportation, such as buses and trains, and people in these regions typically depend on self-owned vehicles for transportation. Car ownership reduces opportunities for these individuals to engage in physical activity [19]. However, previous research has shown that hill slopes and beautiful landscapes encourage walking without using bicycles and that the possibility of "unconscious" physical training is protective against the exacerbation of diabetes [20]. Therefore, in semi-mountainous areas, physical activity that differs from that in flat terrains may have a potential preventive effect against metabolic syndrome. Thus, it is necessary to clarify the association between physical activity and metabolic syndrome in semi-mountainous areas.

This study aimed to identify whether daily physical activity without exercise has a greater association with the prevention of metabolic syndrome than exercise without daily physical activity for the middle-aged and older residents in a semi-mountainous area of Japan.

\section{Methods}

\section{Participants and data sources}

This cross-sectional study used data from a specific health checkup from July to November 2017, provided by the health department of a local authority at a semimountainous, agricultural, rural community in Japan. Based on the explanation by the Ministry of Agriculture, Forestry and Fisheries of Japan [21] and the Japanese Ministry of Health, Labour and Welfare (MHLW) [22], we defined a semi-mountainous area as a place mostly covered with slopes that was neither urban nor open plain. It is usually located on the upstream river and occupies about $70 \%$ of Japan's territory.

The specific health checkup targeted residents aged 4074 years covered by the national health insurance of Japan and were aimed at early detection and intervention for individuals with a high risk of metabolic syndrome [23]. The specific health checkup data included general information (e.g., age and sex), anthropometric measurements, laboratory values, and responses to a self-reported questionnaire on lifestyle behaviors [23]. Health check and questionnaire data were collected on the same day. Exclusion criteria were set as missing valuables, such as sex, age, or questions concerning physical activity.

\section{Explanatory variables: physical activity types}

We used two dichotomized questions regarding physical activity [23] that were based on the physical activity standards for health specified by the MHLW in 2013 [7]. The questions assessed exercise and daily physical activity. The exercise was assessed using the following question (Q1): "Have you been exercising for at least 1 year, at least 2 days per week, or at least 30 min each time at an intensity that causes slight sweating?" with a dichotomized response of "yes" (with exercise) and "no" (without exercise). Daily physical activity was assessed using the following question (Q2): "Do you walk for at least $1 \mathrm{~h}$ every day or have equivalent physical activities in your daily life?" with a dichotomized response of "yes" (with daily physical activity) and "no" (without daily physical activity) [23].

We classified participants into the following four types according to their answers to the two dichotomized questions of exercise (Q1) and daily physical activity (Q2) (Table 1): inactivity type (I-type, without exercise and daily physical activity), only exercise (E-type, with exercise and without daily physical activity), only daily physical activity type (D-type, without exercise and with daily physical activity), and full physical activity (F-type, with exercise and daily physical activity).

\section{Objective variables: metabolic syndrome and its risk factors}

We used anthropometric measurements and laboratory values to assess metabolic syndrome and its risk factors. 
Table 1 Category of physical activity type

\begin{tabular}{llll}
\hline & & \multicolumn{2}{l}{ Q1. Exercise $^{\text {a }}$} \\
\cline { 3 - 4 } & & With & Without \\
\hline Q2. Daily physical activity & With & F-type & D-type \\
& Without & E-type & I-type
\end{tabular}

a"Q1. Exercise" denotes answers to "Have you been exercising for at least 1 year, at least 2 days per week, or at least 30 min each time at an intensity that causes slight sweating?"

b"Q2. Daily physical activity" denotes answers to "Do you walk for at least $1 \mathrm{~h}$ every day or have equivalent physical activities in your daily life?"

"With" and "Without" denote affirmative and negative answers, respectively. F, $D, E$, and I denote full physical activity, only daily physical activity, only exercise, and inactivity, respectively

These variables included body mass index (BMI), waist circumference, systolic blood pressure, diastolic blood pressure, triglycerides, high-density lipoprotein cholesterol (HDL-C), low-density lipoprotein cholesterol (LDL-C), and glycated hemoglobin (HbA1c).

Participants were classified as having metabolic syndrome if they had an excessive waist circumference $(\geq$ $85 \mathrm{~cm}$ for men, $\geq 90 \mathrm{~cm}$ for women) and met two or more of the following criteria. If only one criterion was met, it was classified as a pre-metabolic syndrome: (1) elevated blood pressure ( $\geq 130 \mathrm{mmHg}$, systolic; $\geq 85$ $\mathrm{mmHg}$, diastolic; or use of antihypertensive drugs); (2) reduced HDL-C levels $(<40 \mathrm{mg} / \mathrm{dL})$, elevated triglyceride levels $(\geq 150 \mathrm{mg} / \mathrm{dL})$, or use of anti-hyperlipidemic drugs; and (3) elevated glucose levels (fasting blood glucose $\geq 110 \mathrm{mg} / \mathrm{dL}, \mathrm{HbA} 1 \mathrm{c} \geq 6.1 \%$, or use of antidiabetic drugs) [24]. According to the criteria of the Japanese MHLW, participants were assigned to four groups: metabolic syndrome, pre-metabolic syndrome, no metabolic syndrome, and undeterminable [24]. The MHLW considers metabolic and pre-metabolic syndromes as important targets to reduce the risk of metabolic syndrome-related diseases [25]. Therefore, in this study, we re-categorized the groups based on a dichotomized variable: "metabolic syndrome: case" (metabolic syndrome and pre-metabolic syndrome) and "metabolic syndrome: non-case" (non-metabolic syndrome). The participants in the undeterminable group were excluded from our analysis.

\section{Statistical analysis}

Cases with missing values were excluded list-wise. The following analyses were stratified according to sex. First, we calculated the descriptive statistics for all variables. Then, we performed bivariate sexstratified analyses using Fisher's exact test or $t$-test to compare sociodemographic characteristics, metabolic syndrome status, and risk factors for metabolic syndrome with the participants' physical activity (exercise and daily physical activity). Next, we performed one-way analyses of variance to demonstrate differences in the prevalence of metabolic syndrome and its risk factors among the four physical activity types by sex, assisted by the post hoc analyses of Tukey's honest significant difference test. Lastly, we conducted binomial logistic regression analyses to identify whether and to what extent the D-type group was more or less likely to have metabolic syndrome than the E-type group. We calculated the unadjusted odds ratio (OR), adjusted OR (AOR), and 95\% confidence interval $(\mathrm{CI})$ for each variable. $P$-values of less than 0.05 were considered to indicate statistical significance. Data were analyzed using $\mathrm{R}$ version 3.6.1 [26].

\section{Results}

Participant characteristics and physical activities

The analysis dataset included data from 636 adults (269 men and 367 women) in the age group of 40-74 years [mean (standard deviation, SD) 66.1 (7.8) years for men, 66.3 (7.1) years for women; Table 2]. No data was excluded from the criteria. The prevalence of metabolic syndrome in men and women was $45.7 \%$ and $15.8 \%$, respectively. The proportion of participants with exercise was $38.7 \%$ and $33.0 \%$ among men and women, respectively, and $52.8 \%$ and $47.1 \%$ of the male and female participants were reported with daily physical activity, respectively.

\section{Proportion of participants with metabolic syndrome by sex and physical activity}

The proportion of participants with metabolic syndrome differed according to physical activity (with/without) and type (Table 3). A lower proportion (9.2\%) of women with daily physical activity had metabolic syndrome than women without daily physical activity (21.6\%). Similarly, men with daily physical activity had a lower prevalence of metabolic syndrome (38.7\%) than those without daily physical activity (53.5\%). The prevalence of metabolic syndrome among women according to the physical activity type significantly differed between the D-type and I-type groups $(P<0.001)$. Although the prevalence among men was significantly different among the four activity types $(P=0.033)$, the significance did not persist in multiple comparisons (Table 3).

\section{Risk factors for metabolic syndrome according to with/ without physical activity}

The risk factors for metabolic syndrome with/without physical activity differed by sex (Table 4). Women with exercise showed significantly lower LDL-C levels $(P=$ 0.001 ), whereas those with daily physical activity had significantly lower values of the five risk factors: BMI, waist circumference, systolic blood pressure, LDL-C, and 
Table 2 Participant characteristics and physical activities $(n=636)$

\begin{tabular}{|c|c|c|c|c|c|}
\hline & \multicolumn{2}{|c|}{ Men $(n=269,42.3 \%)$} & \multicolumn{2}{|c|}{ Women $(n=367,57.7 \%)$} & \multirow{2}{*}{$\begin{array}{l}P \text { for sex- } \\
\text { related } \\
\text { differences }\end{array}$} \\
\hline & $n$ & (\%) & $n$ & (\%) & \\
\hline \multicolumn{6}{|l|}{ Q1. Exercise } \\
\hline With & 104 & $(38.7)$ & 121 & (33.0) & \multirow[t]{2}{*}{0.154} \\
\hline without & 165 & $(61.3)$ & 246 & $(67.0)$ & \\
\hline \multicolumn{6}{|l|}{ Q2. Daily physical activity ${ }^{a}$} \\
\hline With & 142 & $(52.8)$ & 173 & $(47.1)$ & \multirow[t]{2}{*}{0.173} \\
\hline Without & 147 & $(54.6)$ & 194 & (52.9) & \\
\hline \multicolumn{6}{|l|}{ Metabolic syndrome $^{b}$} \\
\hline Case & 123 & $(45.7)$ & 58 & (15.8) & \multirow[t]{3}{*}{$<0.001$} \\
\hline \multirow[t]{2}{*}{ Non-case } & 146 & $(54.3)$ & 309 & $(84.2)$ & \\
\hline & mean & (SD) & mean & (SD) & \\
\hline Age, years & 66.1 & (7.8) & 66.3 & (7.1) & 0.001 \\
\hline Body mass index, $\mathrm{kg} / \mathrm{m}^{2}$ & 23.3 & (3.0) & 22.1 & (3.5) & 0.017 \\
\hline Waist circumference, cm & 85.0 & (8.0) & 81.4 & (9.8) & 0.014 \\
\hline Systolic blood pressure, mmHg & 131.3 & $(16.5)$ & 129.5 & (16.0) & 0.004 \\
\hline Diastolic blood pressure, $\mathrm{mmHg}$ & 76.5 & $(11.1)$ & 73.3 & $(10.5)$ & 0.014 \\
\hline Triglyceride, mg/dL & 135.5 & $(88.2)$ & 102.4 & $(57.2)$ & 0.088 \\
\hline $\mathrm{HDL}-\mathrm{C}, \mathrm{mg} / \mathrm{dL}$ & 58.2 & (15.8) & 68.7 & $(16.4)$ & 0.052 \\
\hline $\mathrm{LDL}-\mathrm{C}, \mathrm{mg} / \mathrm{dL}$ & 117.6 & $(30.7)$ & 119.4 & $(29.7)$ & 0.005 \\
\hline $\mathrm{HbA} 1 \mathrm{c}, \%$ & 6.0 & $(0.8)$ & 5.8 & $(0.5)$ & 0.011 \\
\hline
\end{tabular}

HDL-C high-density lipoprotein cholesterol, LDL-C low-density lipoprotein cholesterol, HbA1C glycated hemoglobin

a"Q1. Exercise" and "Q2. Daily physical activity": see Table 1

${ }^{b}$ Metabolic syndrome: case (metabolic syndrome and pre-metabolic syndrome), non-case (non-metabolic syndrome)

${ }^{c} P$ for sex-related difference, independent $t$-test for continuous variables, or Fisher's exact test for categorical variables. Boldface indicates statistically significant differences

HbA1c. There were no significant differences among the male participants (Table 4).

\section{Association between risk factors for metabolic syndrome according to physical activity type}

Table 5 shows the mean differences in the prevalence of risk factors for metabolic syndrome according to the physical activity type. F-type women had significantly lower LDL-C levels than I-type women. Furthermore, participants in the D-type group had significantly lower BMI, lower waist circumference, and higher HDL-C measurements than those in the I-type group.

\section{ORs of physical activity types to prevent metabolic syndrome by sex-specific measures}

As shown in Table 6, logistic regression analysis revealed that women in the D-type group were less likely to have metabolic syndrome $(\mathrm{AOR}=0.24,95 \% \mathrm{CI}, 0.06-0.85)$ than those in the E-type group. However, a significant result was not observed for men.

\section{Discussion}

This study examined whether daily physical activity without exercise had a higher association with the prevention of metabolic syndrome than exercise without daily physical activity in middle-aged and older participants in a semi-mountainous area of Japan. Overall, the prevalence of metabolic syndrome in this study had a large sex-specific difference similar to national prevalence, but both sex prevalence in this study was higher than the national prevalence level: $45.7 \%$, 95\% CI 42.7 to 48.7 in men and $15.8 \%, 95 \%$ CI 13.9 to 17.7 in women. For the national average, the prevalence of men and women was $39.9 \%$ and $11.8 \%$, respectively in 2017 [27]. This is because our study had a higher proportion of older participants than the national average. In this study, the proportion of participants over 60 years old was $86.6 \%$, while that of total examinees in Japan was $35.9 \%$ [27]. Furthermore, regarding Japanese employees' medical insurance, the specific health checkup examinations of those over 60 years was $19.8 \%$, and the total prevalence of metabolic and pre-metabolic syndrome was $38.3 \%$ and $9.8 \%$, in men and women, 
Table 3 Proportions of metabolic syndrome in analyses stratified by sex and physical activity

\begin{tabular}{|c|c|c|c|c|c|c|}
\hline & \multirow{3}{*}{$\begin{array}{l}\text { Total } \\
n\end{array}$} & \multicolumn{4}{|c|}{ Metabolic syndrome $^{b}$} & \multirow{3}{*}{$P$} \\
\hline & & \multicolumn{2}{|c|}{ Case } & \multicolumn{2}{|c|}{ Non-case } & \\
\hline & & $n$ & $(\%)$ & $n$ & $(\%)$ & \\
\hline Men & 269 & 123 & $(45.7)$ & 146 & $(54.3)$ & \\
\hline \multicolumn{7}{|c|}{ Q1. Exercise ${ }^{a}$} \\
\hline With & 104 & 40 & $(38.5)$ & 64 & $(61.5)$ & 0.060 \\
\hline Without & 165 & 83 & $(50.3)$ & 82 & $(49.7)$ & \\
\hline \multicolumn{7}{|c|}{ Q2. Daily physical activity ${ }^{\mathrm{a}}$} \\
\hline With & 142 & 55 & $(38.7)$ & 87 & $(61.3)$ & 0.020 \\
\hline Without & 127 & 68 & $(53.5)$ & 59 & $(46.5)$ & \\
\hline \multicolumn{7}{|c|}{ Physical activity type } \\
\hline I-type ${ }^{a}$ & 112 & 63 & $(56.3)$ & 49 & $(43.8)$ & 0.033 \\
\hline E-type $^{a}$ & 15 & 5 & (33.3) & 10 & (66.7) & \\
\hline D-type ${ }^{a}$ & 53 & 20 & $(37.7)$ & 33 & $(62.3)$ & \\
\hline F-type ${ }^{a}$ & 89 & 35 & $(39.3)$ & 54 & $(60.7)$ & \\
\hline Women & 367 & 58 & $(15.8)$ & 309 & $(84.2)$ & \\
\hline \multicolumn{7}{|c|}{ Q1. Exercise ${ }^{a}$} \\
\hline With & 121 & 18 & $(14.9)$ & 103 & $(85.1)$ & 0.764 \\
\hline Without & 246 & 40 & $(16.3)$ & 206 & $(83.7)$ & \\
\hline \multicolumn{7}{|c|}{ Q2. Daily physical activity ${ }^{a}$} \\
\hline With & 173 & 16 & $(9.2)$ & 157 & (90.8) & 0.001 \\
\hline Without & 194 & 42 & $(21.6)$ & 152 & (78.4) & \\
\hline \multicolumn{7}{|c|}{ Physical activity type } \\
\hline I-type $e^{a}$ & 162 & 35 & $(21.6)$ & 127 & $(78.4)^{d}$ & 0.005 \\
\hline E-type ${ }^{a}$ & 32 & 7 & $(21.9)$ & 25 & $(78.1)$ & \\
\hline D-type ${ }^{a}$ & 84 & 5 & (6.0) & 79 & $(94.0)^{d}$ & \\
\hline F-type ${ }^{a}$ & 89 & 11 & $(12.4)$ & 78 & $(87.6)$ & \\
\hline
\end{tabular}

${ }^{a}$ Q1. Exercise, and Q2. Daily physical activity, I-type, E-type, D-type, and F-type: see Table 1

${ }^{b}$ Metabolic syndrome: case (metabolic syndrome and pre-metabolic syndrome), non-case (non-metabolic syndrome)

${ }^{c} P$-value of the metabolic syndrome in extended Fisher's exact test (all over test). Boldface indicates statistically significant differences

${ }^{d}$ Fisher's exact test for multiple comparisons: $P<0.001$ between I-type and D-type

respectively [27]. The older adults are more susceptible to metabolic syndrome due to decreased glucose tolerance with age [28] and decreased basal metabolism [29].

The main finding of this study was that middle-aged and older women with D-type activity (with daily physical activity and without exercise) were less likely to have metabolic syndrome than those who had E-type activity (without daily physical activity and with exercise) (Table 6). In contrast, the difference was not significant among men. This result could potentially be attributed to the following three possible reasons:

First, exercise does not affect the total amount of physical activity of middle-aged and elderly individuals. Since they might have been exhausted after exercise and unable to remain active, the resulted total amount of physical activity per day did not change. This phenomenon was found elsewhere [30-32]. Exercise had a limited association with metabolic syndrome and its risk factors, that is, exercise affected only one risk factor (Table 4) and did not affect metabolic syndrome (Table 3). Thus, to prevent metabolic syndrome through increased physical activity in middleaged and older women, we recommend promoting daily physical activity rather than an increase in exercise. A previous study has shown that active daily life was important to prevent obesity, independent of exercise [33]. Similarly, active daily life might be important to prevent metabolic syndrome in women. This suggestion is consistent with the recommendation by the World Health Organization [13] and the Japanese MHLW [7], which encourages people to be more active in daily life for a long and healthy life.

Second, the characteristics of the daily physical activity of women may differ from those of the physical activity 
Table 4 Mean values of risk factors for metabolic syndrome in analyses stratified by sex and physical activity

\begin{tabular}{|c|c|c|c|c|c|c|c|c|c|c|}
\hline & \multicolumn{5}{|c|}{ Men $(n=269)$} & \multicolumn{5}{|c|}{ Women $(n=367)$} \\
\hline & \multicolumn{2}{|l|}{ With } & \multicolumn{2}{|c|}{ Without } & \multirow[t]{2}{*}{$P^{b}$} & \multicolumn{2}{|l|}{ With } & \multicolumn{2}{|c|}{ Without } & \multirow[t]{2}{*}{$P^{b}$} \\
\hline & Mean & (SD) & Mean & (SD) & & Mean & (SD) & Mean & (SD) & \\
\hline Q1. Exercise ${ }^{a}, n$ & \multicolumn{2}{|c|}{104} & \multicolumn{2}{|c|}{165} & & \multicolumn{2}{|c|}{121} & \multicolumn{2}{|c|}{246} & \\
\hline Body mass index, $\mathrm{kg} / \mathrm{m}^{2}$ & 23.3 & (3.0) & 23.3 & $(3.0)$ & 0.809 & 21.9 & $(3.2)$ & 22.1 & (3.6) & 0.600 \\
\hline Waist circumference, cm & 84.7 & $(7.8)$ & 85.1 & $(8.2)$ & 0.741 & 81.6 & (9.6) & 81.3 & $(10.0)$ & 0.932 \\
\hline Systolic blood pressure, $\mathrm{mmHg}$ & 133.0 & $(15.7)$ & 130.3 & $(17.0)$ & 0.279 & 129.7 & (15.0) & 129.4 & (16.5) & 0.463 \\
\hline Diastolic blood pressure, $\mathrm{mmHg}$ & 76.6 & $(10.4)$ & 76.4 & $(11.6)$ & 0.742 & 73.0 & $(10.4)$ & 73.4 & $(10.5)$ & 0.509 \\
\hline Triglyceride, mg/dL & 135.8 & $(100.7)$ & 135.3 & $(79.6)$ & 0.898 & 99.8 & $(55.0)$ & 103.7 & $(58.4)$ & 0.430 \\
\hline $\mathrm{HDL}-\mathrm{C}, \mathrm{mg} / \mathrm{dL}$ & 59.3 & $(13.9)$ & 57.6 & $(16.8)$ & 0.357 & 67.8 & $(15.9)$ & 69.2 & $(16.7)$ & 0.482 \\
\hline $\mathrm{LDL}-\mathrm{C}, \mathrm{mg} / \mathrm{dL}$ & 113.8 & $(30.5)$ & 120.0 & $(30.7)$ & 0.261 & 112.4 & (25.5) & 122.8 & $(31.1)$ & 0.001 \\
\hline $\mathrm{HbA} 1 \mathrm{c}, \%$ & 5.9 & $(0.7)$ & 6.0 & $(0.9)$ & 0.226 & 5.8 & $(0.4)$ & 5.8 & $(0.5)$ & 0.222 \\
\hline Q2. Daily physical activity ${ }^{\mathrm{a}}, n$ & \multicolumn{2}{|c|}{142} & \multicolumn{2}{|c|}{127} & & \multicolumn{2}{|c|}{173} & \multicolumn{2}{|c|}{194} & \\
\hline Body mass index, $\mathrm{kg} / \mathrm{m}^{2}$ & 23.1 & (3.0) & 23.6 & (3.3) & 0.248 & 21.4 & $(3.2)$ & 22.6 & (3.6) & 0.001 \\
\hline Waist circumference, cm & 84.2 & $(7.2)$ & 85.9 & (8.9) & 0.102 & 79.6 & $(9.2)$ & 82.9 & $(10.1)$ & $<0.001$ \\
\hline Systolic blood pressure, mmHg & 131.1 & $(15.8)$ & 131.6 & $(17.3)$ & 0.629 & 127.9 & $(16.9)$ & 131.0 & $(15.1)$ & 0.039 \\
\hline Diastolic blood pressure, $\mathrm{mmHg}$ & 75.9 & $(11.4)$ & 77.2 & $(10.8)$ & 0.402 & 72.4 & $(10.2)$ & 74.1 & $(10.7)$ & 0.104 \\
\hline Triglyceride, mg/dL & 126.4 & $(81.6)$ & 145.6 & $(94.4)$ & 0.086 & 96.6 & $(55.2)$ & 107.6 & (58.6) & 0.064 \\
\hline $\mathrm{HDL}-\mathrm{C}, \mathrm{mg} / \mathrm{dL}$ & 59.9 & $(14.2)$ & 56.4 & $(17.2)$ & 0.070 & 70.2 & $(15.8)$ & 67.4 & $(16.8)$ & 0.097 \\
\hline LDL cholesterol, mg/dL & 118.5 & $(29.7)$ & 116.6 & $(31.9)$ & 0.331 & 113.5 & $(27.2)$ & 124.7 & (30.9) & $<0.001$ \\
\hline $\mathrm{HbA} 1 \mathrm{c}, \%^{\mathrm{b}}$ & 5.9 & $(0.7)$ & 6.1 & (1.0) & 0.268 & 5.7 & $(0.4)$ & 5.8 & $(0.5)$ & 0.014 \\
\hline
\end{tabular}

$H D L-C$ high-density lipoprotein cholesterol, $L D L-C$ low-density lipoprotein cholesterol, HbA1C glycated hemoglobin

${ }^{a}$ "Q1. Exercise" and "Q2. Daily physical activity": see Table 1

${ }^{\mathrm{b}} P$ independent $t$-test adjusted by age. Boldface indicates statistically significant differences

of men. The question used in our study, Q2 "Do you walk for at least $1 \mathrm{~h}$ every day or have equivalent physical activities in your daily life?" includes activities that are undertaken daily, e.g., housework [23]. The intensity of physical activity of housework ranges from light to moderate-vigorous [34]. Women spend longer durations in housework than men [35-37]. More than that of men, the lifestyle of women ensures that they undertake more frequent light to moderate-vigorous physical activities [38]. A study has shown that housework enhances the association of physical activity with metabolic syndrome by increasing the total energy expenditure [39]. Other studies have found that light intensity $[40,41]$ or more than 10 min of consecutive moderate-vigorous physical activity [42] prevents metabolic syndrome.

Third, unlike flat urban or suburban areas, a semimountainous area has many slopes and steps, enhancing routine up and down movement on foot or by bicycle, leading to a higher intensity of daily physical activity [34]. Furthermore, the presence and availability of destinations, such as commercial and leisure facilities in the neighborhood, are associated with physical activity promotion in older adults [43, 44]. However, few destinations are available in semi-mountainous areas [45]; the only destinations available may be their own farms or the houses of their neighbors. In the daily life of female residents of semi-mountainous areas, active daily agricultural farm work for daily meals, gardening a larger yard, and visiting distant neighbors may enhance daily physical activity.

In our study, it is possible that daily physical activity increased the total energy expenditure of women involved in housework or that light-intensity daily physical activity and moderate-vigorous physical activity derived from housework were related to the prevention of metabolic syndrome. Thus, an intervention focusing on household chores is a promising way to prevent metabolic syndrome among women in semi-mountainous areas.

This study suggests that enhancing daily physical activity may be a key to preventing metabolic syndrome in middle-aged and older individuals residing in semimountainous areas of Japan. A more detailed evaluation of the daily physical activities of women, including content (e.g., housework), intensity, and total time of daily physical activity, is necessary in further research. 
Table 5 Mean differences in the risk factors for metabolic syndrome by physical activity type in sex-stratified analyses

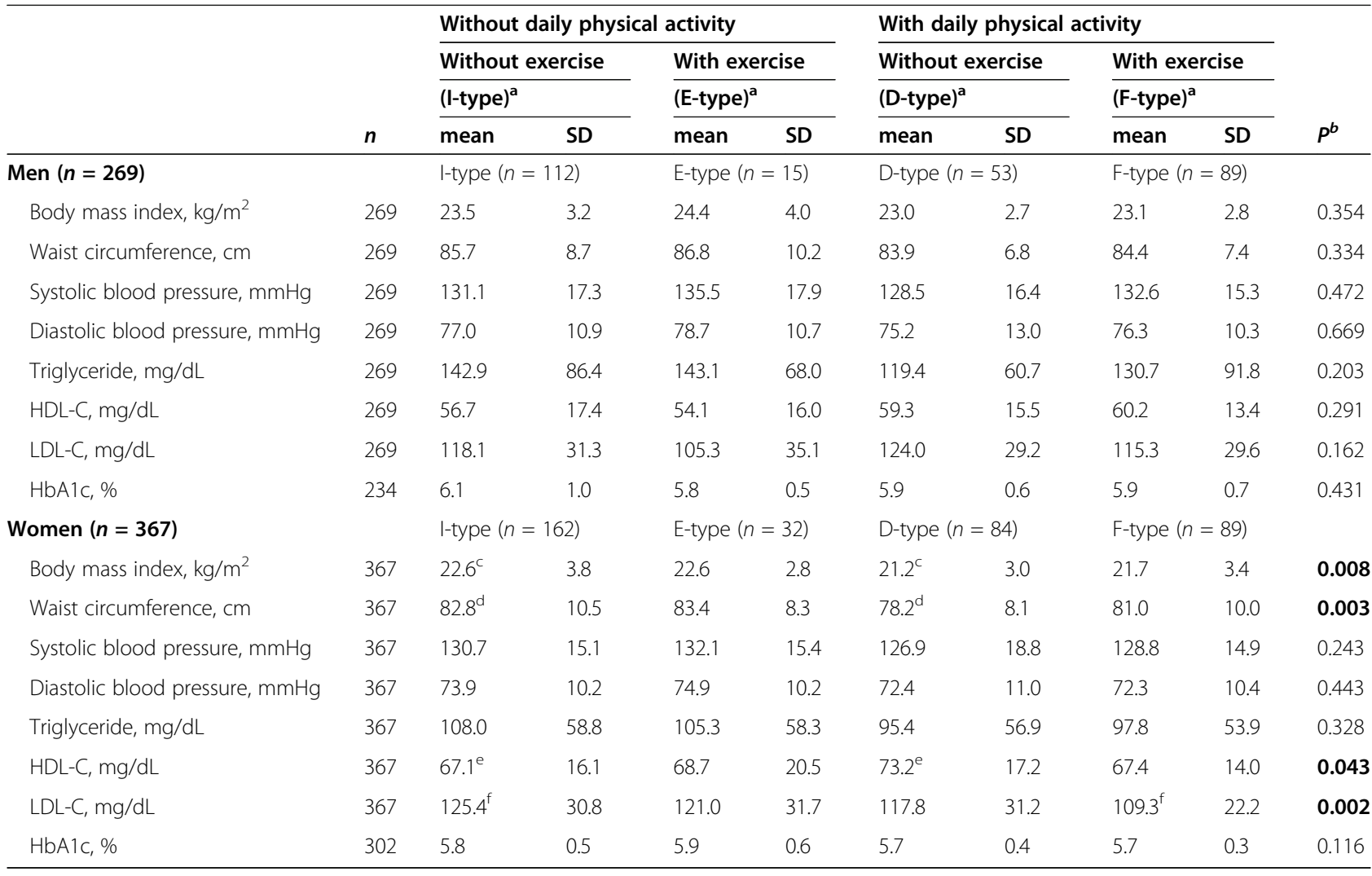

HDL-C high-density lipoprotein cholesterol, LDL-C low-density lipoprotein cholesterol, HbA1c glycated hemoglobin

a-type, D-type, E-type, and F-type: see Table 1

${ }^{b} P$ One-way analysis of variance adjusted by age. Boldface indicates statistically significant differences

Tukey's honest significant difference test for multiple comparisons: ${ }^{\mathrm{C}} P<0.01$ between I-type and D-type; ${ }^{\mathrm{d}} P<0.01$ between I-type and $\mathrm{D}$-type; ${ }^{\mathrm{e}} P<0.05$ between

I-type and D-type; ${ }^{f} P<0.001$ between I-type and F-type

This study has several potential limitations. First, we could not explain the causal relationship between the daily physical activity and metabolic syndrome and its risk factors because of the cross-sectional design. Second, this study used data from a self-reported questionnaire, which could not assess the actual accurate amount and intensity, namely metabolic equivalents (METs), total time, and content of physical activities. Although the validity of the questionnaire has been confirmed and is used officially in Japan, the accuracy is rather limited [46]. Third, the generalizability of the study findings could be limited because our study examined only one area. In further research, emphasis should be placed on objective physical activity measurements, including light-intensity physical activity, to assess the association between daily physical activity and metabolic syndrome and its risk factors.

\section{Conclusions}

Among those living in a semi-mountainous area of Japan, middle-aged and older women with daily physical

Table 6 Sex-stratified odds ratios of physical activity types for the prevention of metabolic syndrome

\begin{tabular}{|c|c|c|c|c|c|c|c|c|c|c|c|c|c|c|c|c|}
\hline & \multicolumn{16}{|c|}{ Metabolic syndrome $^{a}$} \\
\hline & \multicolumn{8}{|c|}{ Men $(n=68)$} & \multicolumn{8}{|c|}{ Women $(n=116)$} \\
\hline & OR & \multicolumn{2}{|c|}{$95 \% \mathrm{Cl}$} & $P$ & AOR & \multicolumn{2}{|c|}{$95 \% \mathrm{Cl}$} & $P$ & OR & \multicolumn{2}{|c|}{$95 \% \mathrm{Cl}$} & $P$ & AOR & \multicolumn{2}{|c|}{ 95\% Cl } & $P$ \\
\hline E-type ${ }^{b}$ & 1.00 & \multicolumn{2}{|c|}{ (reference) } & & 1.00 & \multicolumn{2}{|c|}{ (reference) } & & 1.00 & \multicolumn{2}{|c|}{ (reference) } & & 1.00 & \multicolumn{2}{|c|}{ (reference) } & \\
\hline D-type ${ }^{b}$ & 0.65 & 0.30 & 1.46 & 0.285 & 1.21 & 0.37 & 4.37 & 0.753 & 0.23 & 0.30 & 0.77 & 0.018 & 0.24 & 0.06 & 0.85 & 0.028 \\
\hline
\end{tabular}

Boldface indicates statistically significant differences

$O R$ odds ratio, $A O R$ adjusted odds ratio by age, $\mathrm{Cl}$ confidence interval

${ }^{\text {a}}$ The dependent variables are defined by "the presence of metabolic syndrome or pre-metabolic syndrome: case" and "non-metabolic syndrome: non-case"

${ }^{\mathrm{b}}$ The independent variable is the type of physical activity. D-type and E-type: see Table 1 
activity and without exercise had lower BMIs, smaller waist circumferences, higher HDL-C levels, and a lower prevalence of metabolic syndrome than those without daily physical activity and with exercise. Compared to middle-aged and older women with exercise in this region, those with daily physical activity may effectively prevent metabolic syndrome.

\section{Abbreviations}

AOR: Adjusted odds ratio; BMI: Body mass index; Cl: Confidence interval; HbA1c: Glycated hemoglobin; HDL-C: High-density lipoprotein cholesterol; LDL-C: Low-density lipoprotein cholesterol; MHLW: Ministry of Health, Labour and Welfare; OR: Odds ratio; SD: Standard deviation

\section{Acknowledgements}

We are grateful to the residents of the town for their participation in this study and to the staff of the health department of the local authority for their cooperation.

\section{Authors' contributions}

NK, RN, ST and MM designed the study. NK and ST conducted data analyses. NK, ST, RN, MM, and SO interpreted the results. RN supervised the whole project. NK and MM drafted the manuscript, and all authors revised it critically for important intellectual content and have read and approved the final manuscript.

\section{Funding}

This research did not receive any specific grants from funding agencies in the public, commercial, or not-for-profit sectors.

\section{Availability of data and materials}

The datasets analyzed during the current study are not publicly available due to the necessity of permission from the town. They are not allowed for secondary usage.

\section{Ethics approval and consent to participate}

This study used data from a specific health checkup with the permission of the health department of the local authority. Prior to data collection, we informed the potential participants about the research purpose and methods through an opt-out notice that was posted on the town's webpage. We received de-identified data after the study protocol was approved by the Clinical Research Ethics Review Committee of Mie University Hospital (approval no. U2019-025).

\section{Consent for publication}

Not applicable.

\section{Competing interests}

The authors declare no competing interests.

\section{Received: 23 November 2020 Accepted: 14 February 2021}

Published online: 10 April 2021

\section{References}

1. Amirfaiz S, Shahril MR. Objectively measured physical activity, sedentary behavior, and metabolic syndrome in adults: systematic review of observational evidence. Metab Syndr Relat Disord. 2019:17:1-21.

2. World Health Organization. Prevalence of insufficient physical activity among adults data by country. Updated November 5, 2018. https://apps. who.int/gho/data/node.main.A893 Accessed 8 Aug 2020.

3. Guthold R, Stevens GA, Riley LM, Bull FC. Worldwide trends in insufficient physical activity from 2001 to 2016: a pooled analysis of 358 populationbased surveys with 1.9 million participants. Lancet Glob Health. 2018;6: e1077-86.

4. Paley CA, Johnson Ml. Abdominal obesity and metabolic syndrome: exercise as medicine? BMC Sports Sci Med Rehabil. 2018;10:7.

5. World Health Organization. Global recommendations on physical activity for health. 2010 https://apps.who.int/iris/bitstream/handle/10665/44399/ 9789241599979_eng.pdf Accessed 8 Aug 2020.
6. World Health Organization. Global action plan on physical activity 20182030: more active people for a healthier world. 2018. https://apps.who.int/ iris/handle/10665/272722. Accessed 8 Aug 2020.

7. Ministry of Health Labour, and Welfare of Japan. Physical activity guideline for health promotion 2013 and active guide. https://www.mhlw.go.jp/stf/ houdou/2r9852000002xple.html Accessed 22 Aug 2020.

8. Van Namen M, Prendergast $L$, Peiris C. Supervised lifestyle intervention for people with metabolic syndrome improves outcomes and reduces individual risk factors of metabolic syndrome: a systematic review and meta-analysis. Metabolism. 2019;101:153988.

9. Wewege MA, Thom JM, Rye KA, Parmenter BJ. Aerobic, resistance or combined training: a systematic review and meta-analysis of exercise to reduce cardiovascular risk in adults with metabolic syndrome. Atherosclerosis. 2018;274:162-71.

10. Zhang D, Liu X, Liu Y, Sun X, Wang B, Ren Y, et al. Leisure-time physical activity and incident metabolic syndrome: a systematic review and doseresponse meta-analysis of cohort studies. Metabolism. 2017:75:36-44.

11. González K, Fuentes J, Márquez JL. Physical inactivity, sedentary behavior and chronic diseases. Korean J Fam Med. 2017;38:111-5.

12. Katzmarzyk PT, Powell KE, Jakicic JM, Troiano RP, Piercy K, Tennant B, et al. Sedentary behavior and health: update from the 2018 Physical Activity Guidelines Advisory Committee. Med Sci Sports Exerc. 2019;51:1227-41.

13. World Health Organization. WHO guidelines on physical activity and sedentary behaviour. https://www.who.int/publications/i/item/978924001 5128. Accessed 1 Jan 2021.

14. World Health Organization. WHO guidelines on physical activity and sedentary behaviour: web annex: evidence profiles. 2020. World Health Organization https://apps.who.int/iris/handle/10665/336657. Accessed 1 Jan 2021.

15. Bull FC, Al-Ansari SS, Biddle S, Borodulin K, Buman MP, Cardon G, et al. World Health Organization 2020 guidelines on physical activity and sedentary behaviour. Br J Sports Med. 2020;54:1451-62.

16. Koohsari MJ, Sugiyama T, Shibata A, Ishii K, Liao Y, Hanibuchi T, et al. Associations of street layout with walking and sedentary behaviors in an urban and a rural area of Japan. Health Place. 2017:45:64-9.

17. Martin SL, Kirkner GJ, Mayo K, Matthews CE, Durstine JL, Hebert JR. Urban, rural and regional variations in physical activity. J Rural Health. 2005;21:239-44.

18. Carlson SA, Whitfield GP, Peterson EL, Ussery EN, Watson KB, Berrigan $D$, et al. Geographic and urban-rural differences in walking for leisure and transportation. Am J Prev Med. 2018;55:887-95.

19. Anderson ML, Lu F, Yang J. Physical activity and weight following car ownership in Beijing, China: quasi-experimental cross sectional study. BMJ. 2019;367:16491.

20. Fujiwara T, Takamoto I, Amemiya A, Hanazato M, Suzuki N, Nagamine $Y$, et al. Is a hilly neighborhood environment associated with diabetes mellitus among older people? Results from the JAGES 2010 study. Soc Sci Med. 2017;182:45-51.

21. Ministry of Agriculture, Forestry and Fisheries. https://www.maff.go.jp/j/ nousin/tyusan/siharai_seido/s_about/cyusan/. Accessed 28 Jan 2021.

22. Ministry of Health, Labour and Welfare of Japan. White paper on suicide prevention in 2016, 74-88. https://www.mhlw.go.jp/wp/hakusyo/jisatsu/16/ index.html. Accessed 28 Jan 2021.

23. Ministry of Health, Labour and Welfare of Japan. Standard medical examination and health guidance program [2018 version]. 2018. https:// www.mhlw.go.jp/content/10900000/000496784.pdf Accessed 10 Aug 2020.

24. Ministry of Health, Labour and Welfare of Japan. Guide for smooth implementation of specific health checkups and specific health guidance [ver3.1]. Updated 31 Mar 2020. https://www.mhlw.go.jp/content/12400000/ 000616991.pdf. Accessed 22 Aug 2020.

25. Ministry of Health Labour, and Welfare of Japan. The point of view of Ministry about metabolic syndrome-classification and lifestyle-related health guidance. https://www.mhlw.go.jp/shingi/2005/08/s0826-9d.html. Accessed 28 Jan 2021.

26. R Core Team. R: A language and environment for statistical computing. Vienna: R Foundation for Statistical Computing; 2020. https://www.r-project. org/. Accessed 8 Aug 2020

27. Ministry of Health, Labour and Welfare of Japan. Implementation status of specific health checkups and specific health guidance in 2017. https://www.mhlw.go.jp/stf/ seisakunitsuite/bunya/0000173202_00002.html. Accessed 29 Jan 2021.

28. Basu R, Breda E, Oberg AL, Powell CC, Man CD, Basu A, et al. Mechanisms of the age associated deterioration in glucose tolerance: contribution of alterations in insulin secretion, action, and clearance. Diabetes. 2003;52:1738-48. 
29. Roberts SB, Dallal GE. Energy requirements and aging. Public Health Nutr. 2005;8:1028-36.

30. Meijer EP, Westerterp KR, Verstappen FT. Effect of exercise training on total daily physical activity in elderly humans. Eur J Appl Physiol Occup Physiol. 1999;80:16-21

31. Westerterp KR. Physical activity as determinant of daily energy expenditure. Physiol Behav. 2008;93:1039-43.

32. Goran MI, Poehlman ET. Endurance training does not enhance total energy expenditure in healthy elderly persons. Am J Physiol. 1992;263:E950-7.

33. Banks E, Lim L, Seubsman SA, Bain C, Sleigh A. Relationship of obesity to physical activity, domestic activities, and sedentary behaviours: crosssectional findings from a national cohort of over 70,000 Thai adults. BMC Public Health. 2011;11:762.

34. Ainsworth BE, Haskell WL, Herrmann SD, Meckes N, Bassett Jr DR, TudorLocke C, et al. 2011 Compendium of physical activities: a second update of codes and MET values. Med Sci Sports Exerc. 2011;43:1575-81.

35. Statistics Bureau, Ministry of Internal Affairs and Communications of Japan. Survey on time use and leisure activities. 2016. http://www.stat.go.jp/ english/data/shakai/2016/pdf/timeuse-a2016.pdf Accessed 22 Aug 2020.

36. Tanimoto M. Peasant society in Japan's economic development: with special focus on rural labour and finance markets. Int J Asian Stud. 2018;15:229-53.

37. Organization for Economic Cooperation and Development. Employment: time spent in paid and unpaid work, by sex. 2020. https://stats.oecd.org/ index.aspx?queryid=54757\# Accessed 22 Aug 2020.

38. Machida M, Takamiya T, Amagasa S, Kikuchi H, Fukushima N, Odagiri Y, et al. Descriptive epidemiology of accelerometer-measured moderate to vigorous physical activity in Japanese older adults. Nihon Ronen Igakkai Zasshi. 2018; 55:584-93.

39. Serrano-Sánchez JA, Fernández-Rodríguez MJ, Sanchis-Moysi J, RodríguezPérez MDC, Marcelino-Rodríguez I, Cabrera de León A. Domain and intensity of physical activity are associated with metabolic syndrome: a population-based study. Plos One. 2019;14:e0219798.

40. Kim J, Tanabe K, Yokoyama N, Zempo H, Kuno S. Objectively measured light-intensity lifestyle activity and sedentary time are independently associated with metabolic syndrome: a cross-sectional study of Japanese adults. Int J Behav Nutr Phys Act. 2013;10:30.

41. Amagasa S, Machida M, Fukushima N, Kikuchi H, Takamiya T, Odagiri Y, et al. Is objectively measured light-intensity physical activity associated with health outcomes after adjustment for moderate-to-vigorous physical activity in adults? A systematic review. Int J Behav Nutr Phys Act. 2018;15:65.

42. Scheers T, Philippaerts R, Lefevre J. SenseWear-determined physical activity and sedentary behavior and metabolic syndrome. Med Sci Sports Exerc. 2013;45:481-9.

43. Barnett DW, Barnett A, Nathan A, Van Cauwenberg J, Cerin E, Council on Environment and Physical Activity (CEPA) - Older Adults working group. Built environmental correlates of older adults' total physical activity and walking: a systematic review and meta-analysis. Int J Behav Nutr Phys Act. 2017;14:103

44. Tsunoda K, Tsuji T, Kitano N, Mitsuishi Y, Yoon JY, Yoon J, et al. Associations of physical activity with neighborhood environments and transportation modes in older Japanese adults. Prev Med. 2012;55:113-8.

45. Kikuchi H, Nakaya T, Hanibuchi T, Fukushima N, Amagasa S, Oka K, et al. Objectively measured neighborhood walkability and change in physical activity in older Japanese adults: a five-year cohort study. Int J Environ Res Public Health. 2018;15:1814

46. Kawakami R, Miyachi M. Validity of a standard questionnaire to assess physical activity for specific medical checkups and health guidance. Nihon Koshu Eisei Zasshi. 2010;57:891-9.

\section{Publisher's Note}

Springer Nature remains neutral with regard to jurisdictional claims in published maps and institutional affiliations.

Ready to submit your research? Choose BMC and benefit from:

- fast, convenient online submission

- thorough peer review by experienced researchers in your field

- rapid publication on acceptance

- support for research data, including large and complex data types

- gold Open Access which fosters wider collaboration and increased citations

- maximum visibility for your research: over $100 \mathrm{M}$ website views per year

At BMC, research is always in progress.

Learn more biomedcentral.com/submissions 